SAND88-1215

SAND $--88-1215$

Unlimited Release

DE91 000478

\title{
Characterization of a Laser-Beam Spinning Technique
}

\author{
Eldon Brandon \\ Metallurgical Process Division \\ Sandia National Laboratories \\ Albuquerque, NM 87185
}

\begin{abstract}
The objective of this study was to evaluate the beam spinning technique for bridging gaps in butt joints that are $\mathrm{CO}_{2}$ laser-welded. A device was designed and built to circularly oscillate a $\mathrm{CO}_{2}$ laser beam on the plane of a work surface. A series of welds was made using a continuous-wave output power of 805 watts, and the resultant weld bead profile was characterized as a function of three process parameters. From the experimental results, predictor equations were derived for laser-beam spinning speed and amplitude of the beam spinning pattern on the work surface. 'The data collected in this experiment indicate that the width of the weld bead is increased by oscillating the beam and that this increase may be made without significantly reducing the weld penetration. The increased width of the weld may offer a solution to variable gaps in weld joints, which has been a recurring production problem.
\end{abstract}




\section{Contents}

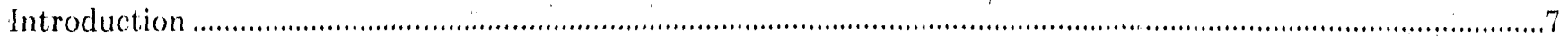

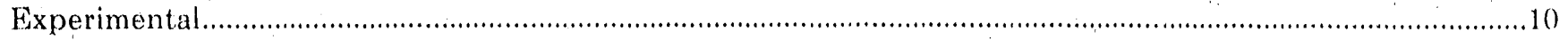

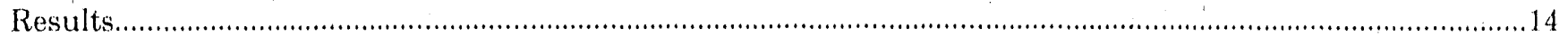

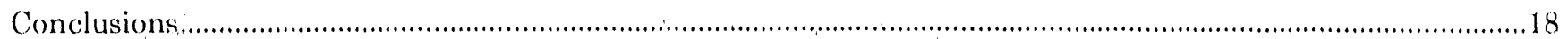

\section{Figures}

1 Schematic of beam path showing effect of travel speed at a constant $3000 \mathrm{rpm}$ spin speed ......................8

2 Beam spinner built by The Welding Institute in Cambridge, England.................................................

3 Schematic of beam spinner built by The Welding Institute .........................................................

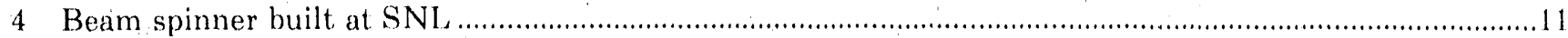

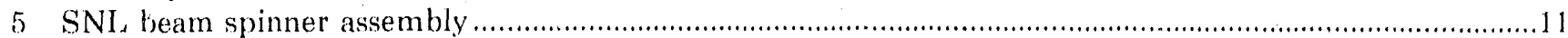

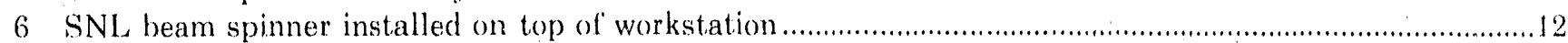

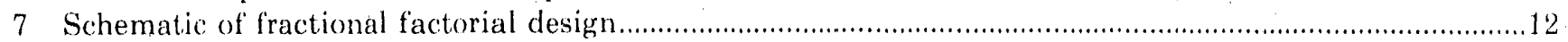

8 Schematic of fractional factorial design showing combinations of parameters ....................................... 2

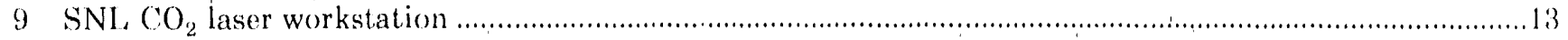

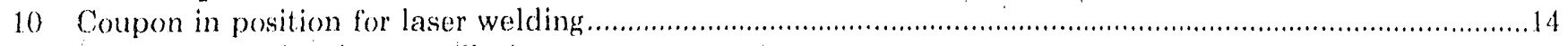

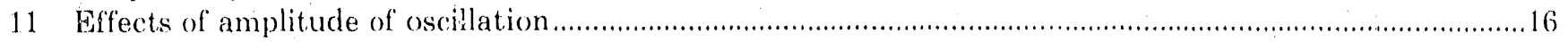

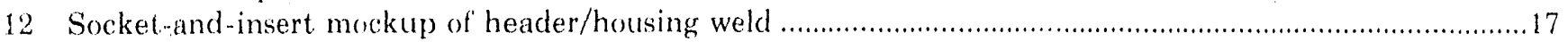

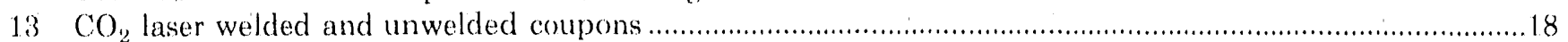




\section{Characterization of a Laser-Beam Spinning Technique}

\section{Introduction}

Our objective was to develop a way to accommodate gaps in the joints of comnector-to-housing welds. These gaps, which may be up to 10 mils wide, are a result of normal machining tolerances in the racetrackshaped welds of the W88 and other firing sets. Typical materials are 17.45' stainless steei for the housing and 304L, stainless steel for the connector. An edgeflange joint design is used with the edges 60 mils high and 20 mils thick. 'The required penetration is 30 mils minimum; the close proximity of glass-to-metal seals limits the maximum temperature during welding.

This application is typiral of Allied-Signal Aerospace Company, Kansas City Division (KCD) production items. $\mathrm{K}(\mathrm{C})$ is $\left(\mathrm{C}_{2}\right.$ laser-beam welding the firing set housings using a Photon Sources V1200 laser operating at 50() -W constant wave power, sharp focus, and 80 ipm travel speed. At these welding parameters, which are dictated by the penetration requirement and the limited heat input, tho random joint gaps sometimes rail to fuse.

Mike Cieslak, Process Metallurgy Division 18333, observed the gap closure problem and discussed machining tolerances with $K(\mathrm{CD}$. After concluding that tighter machining tolerances were not economically feasible, the Process Development Labs in the Metallurgical Process Division 7473 was asked to look into possible solutions.

The primary K(l) contacts were:

J. Samayoa, staff engineer, 1)/844
J. Daumeyer, engineer, D)/844

R. Obenchain, senior project engineer, 1$) / 844$

The SNI, Albuquerque persomel involved were:

M. Cieslak, K(I) technical liaison, Process

Metallurgy, I)iv,

J. Jellison, Supervisor, Process Metallurgy Div.

P. Wilsom, Special Projects Div.

D. Sheldon, Statistics, Computing, and Human Factors loiv.

F. Brandon, welding development, Metallurgical Processeses Div.

M. Reichenbach, Mechanical Process

Fingineering l)iv.

We first tried oscillating the beam in a circular pattern to accommodate the joint gap during welding. As a conceptual aid, the path of a circularly oscillated beam traversing a surface is shown schematically in Figure 1. Circular oscillation may be accomplished by offsetting and rotating the focus lens, as with a boring head attachment used for drilling holes, or by tilting and rotating a bending mirror. We decided to pursue the latter tilting and spinning the final bending mirror, which is located at the lop of the workstation. This approach is not without precedent. (. . J. Davies at The Welding Institute in Cambridge, England, describes a similar device in The Welding Institute Report No. 269/1985, dated March 1985. Figure 2 shows a photo of a beam spinner built by 'The Welding Institute; Figure is shows a schematic of same. 


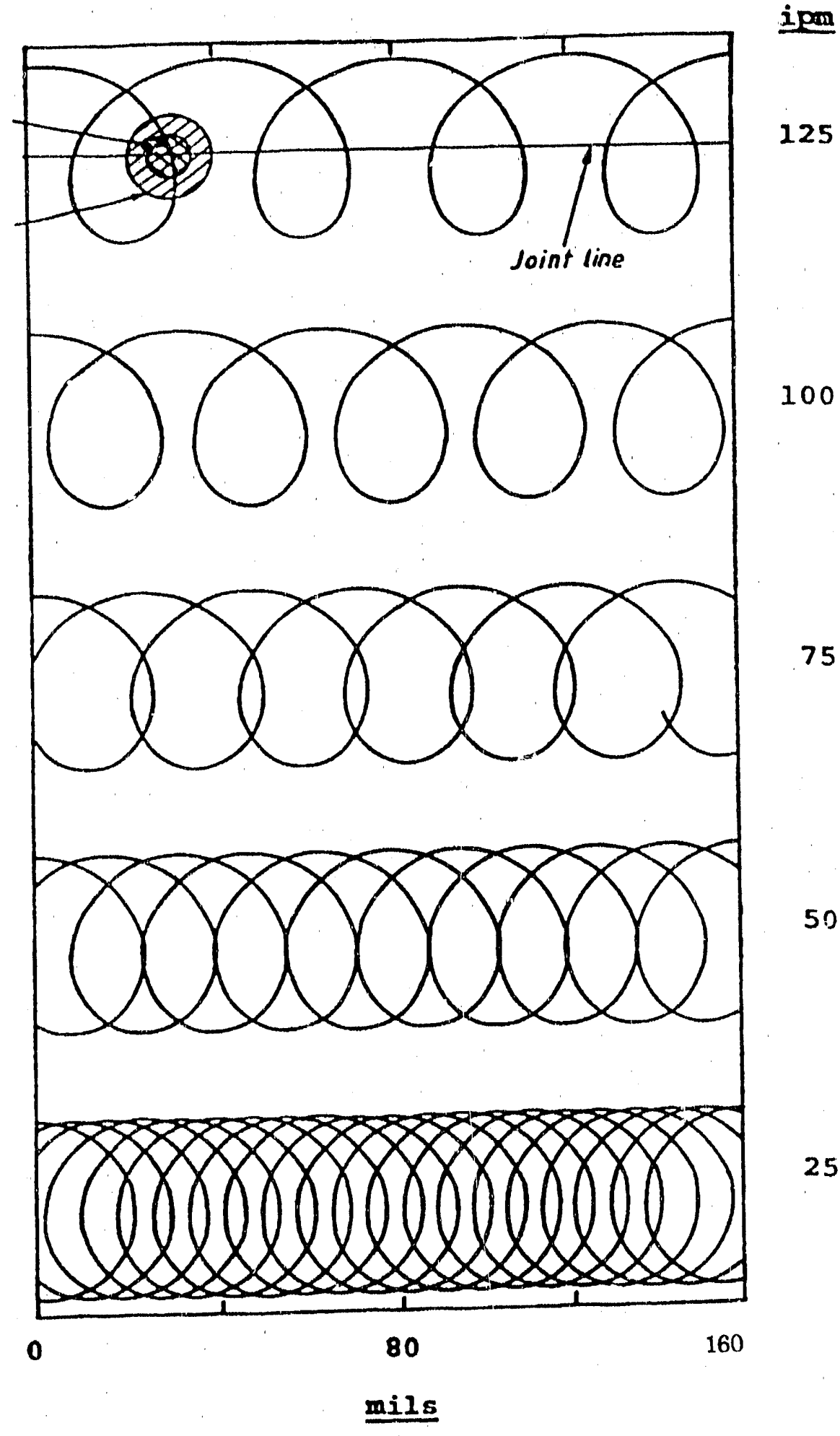

Figure 1. Schematic of beam path showing effect of travel speed at a constant $300(0) \mathrm{rpm}$ spin speed (from Report No. 269/1985), The Welding Institute) 


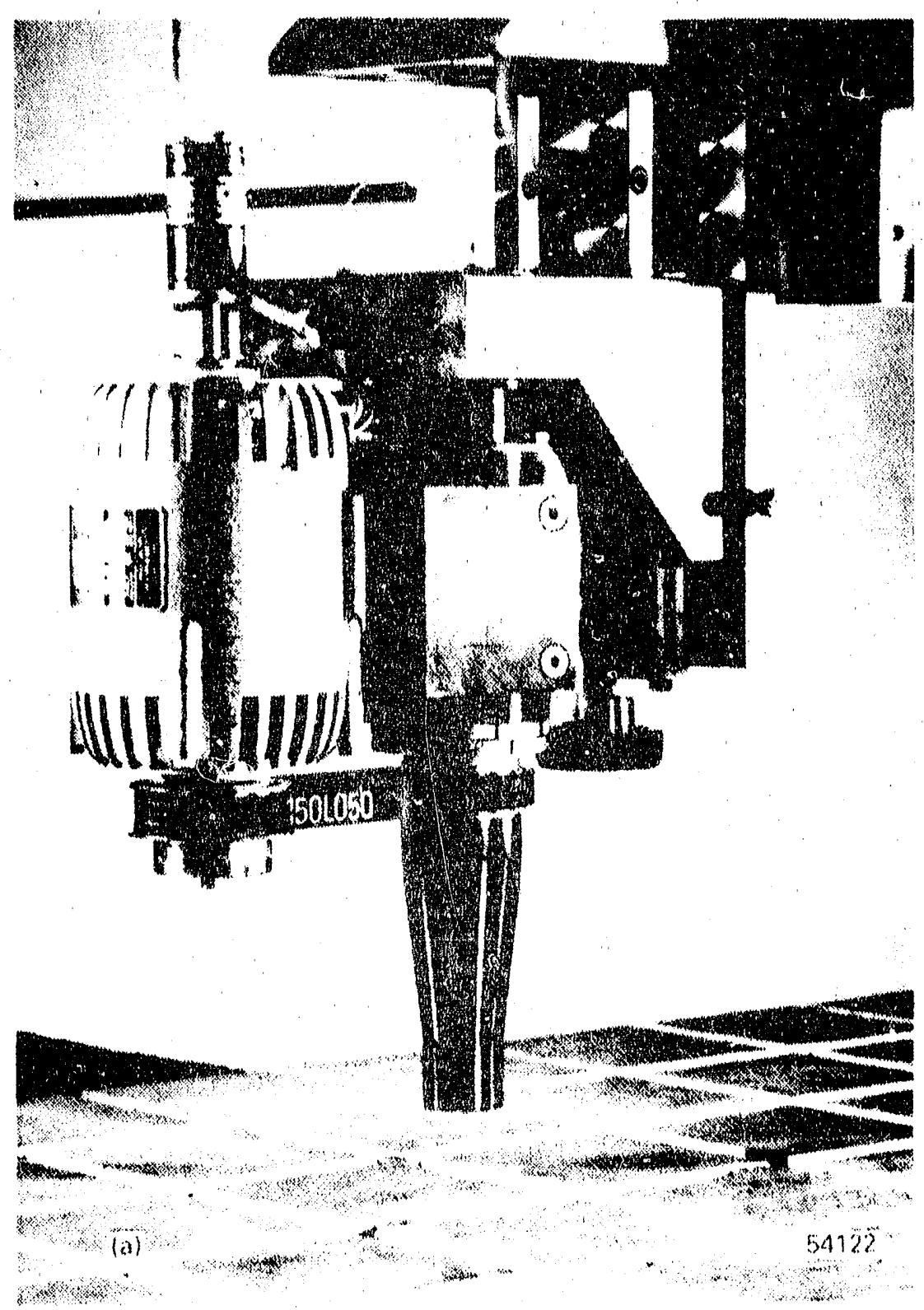

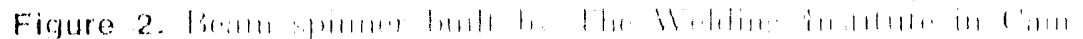

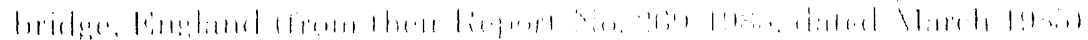




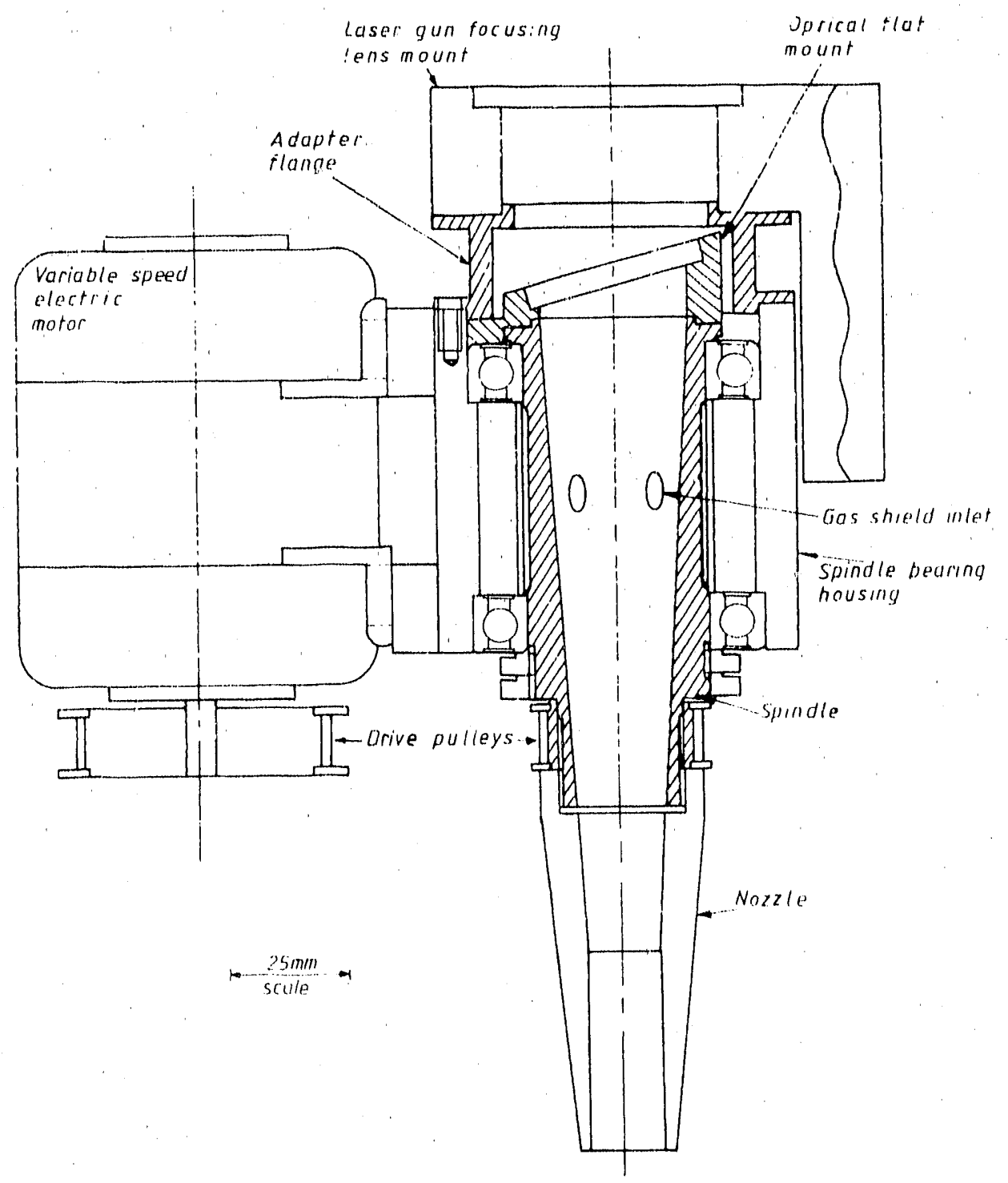

Figure 3. Schematic of beam spinner built by 'The Welding Institute (from their Report No. 269/1985, dated March 1986)

\section{Experimental}

We designed and fabricated a "beam spinner" to rolate the final bending mirror that consisted of an Electro-craft 4586 motor with the mirror clamped in a mirror holder mounted on the output shaft of the motor. An O-ring in the mirror holder cushions the mirror and allows the clamping pressure to adjust the ofliset of the mirror (Figrures 4, 5, and 6). With this device the mirror offset can be varied from 0 to 6 mils and the rotational speed from o to $50(0) \mathrm{rpm}$. 'The heam spinner is a relatively simple apparatus. It occupies little space in the workstation, is capable of traversing a closed-loop path on the workpiece, and requires minimal development.

To analyze the effect on depth of weld ponetration and width of weld bead, we set up a fractiona! factorial design of three variables, each at three lovels. As shown in Figures 7 and 8 , the variables and levels were

$\mathrm{X}_{1}$, mirror offise *

2, 4, 6 mils

$X_{2}$, spin speed $200(0,3500,50000 \mathrm{rpm}$

$X_{3,}$, welding speed

$40,60,80 \mathrm{ipm}$

*The low-to-high measurement at $3 \mathrm{in}$. diameter on the surface of the mirror 


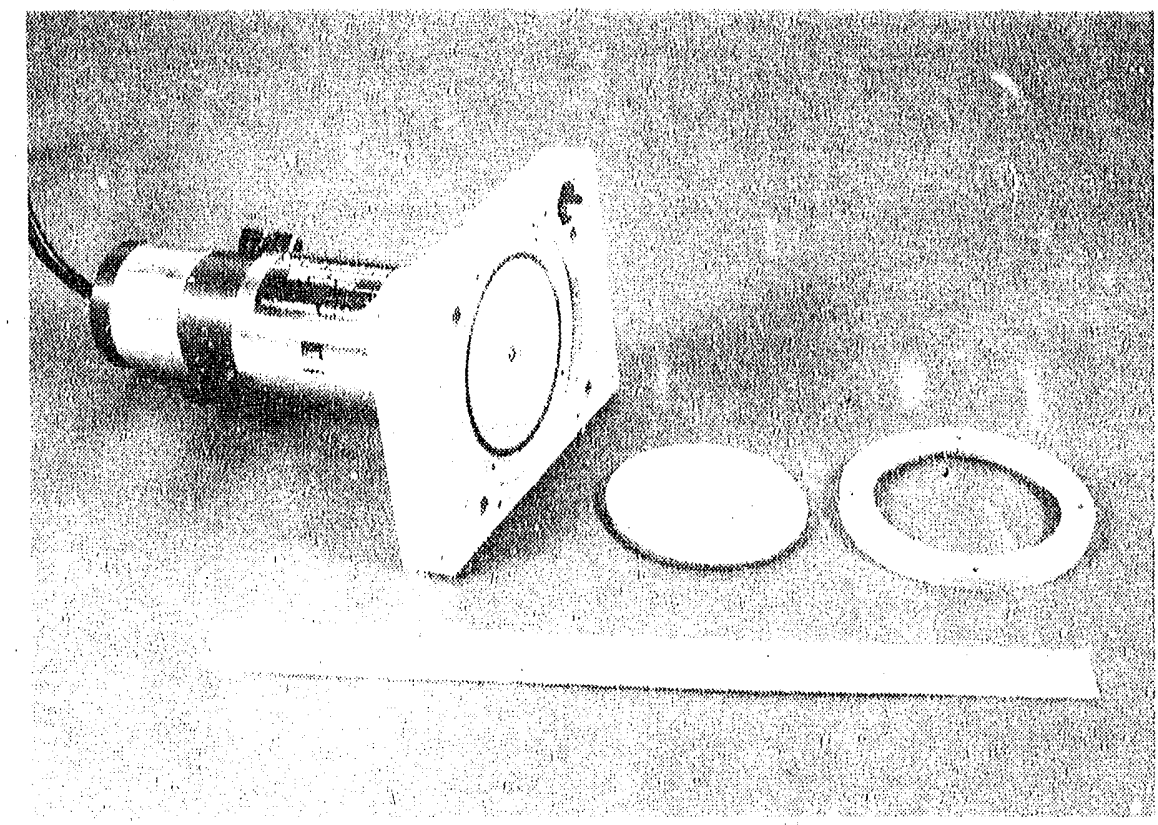

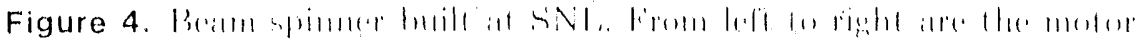

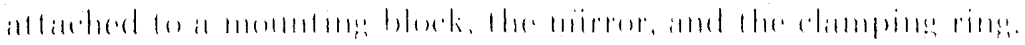

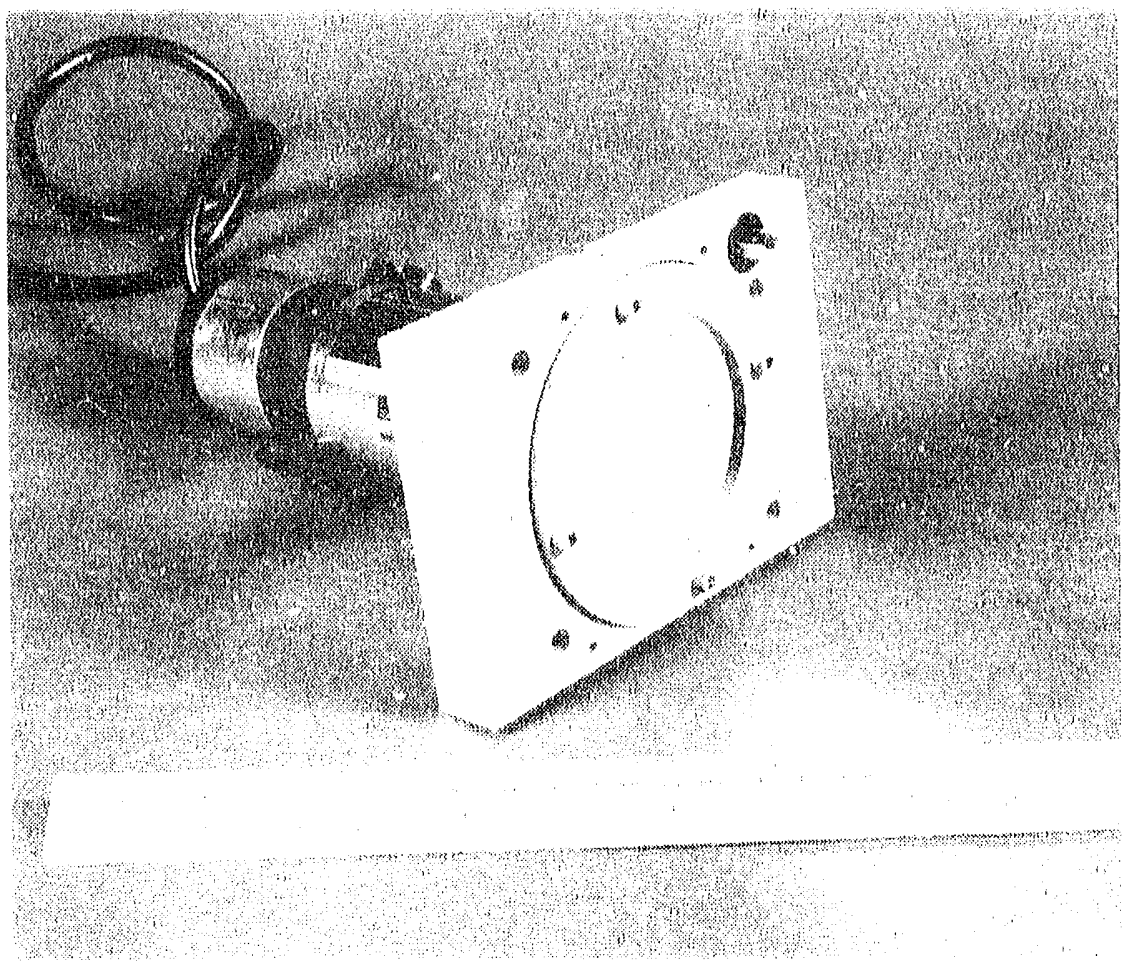

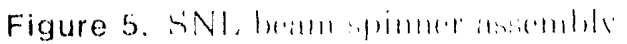




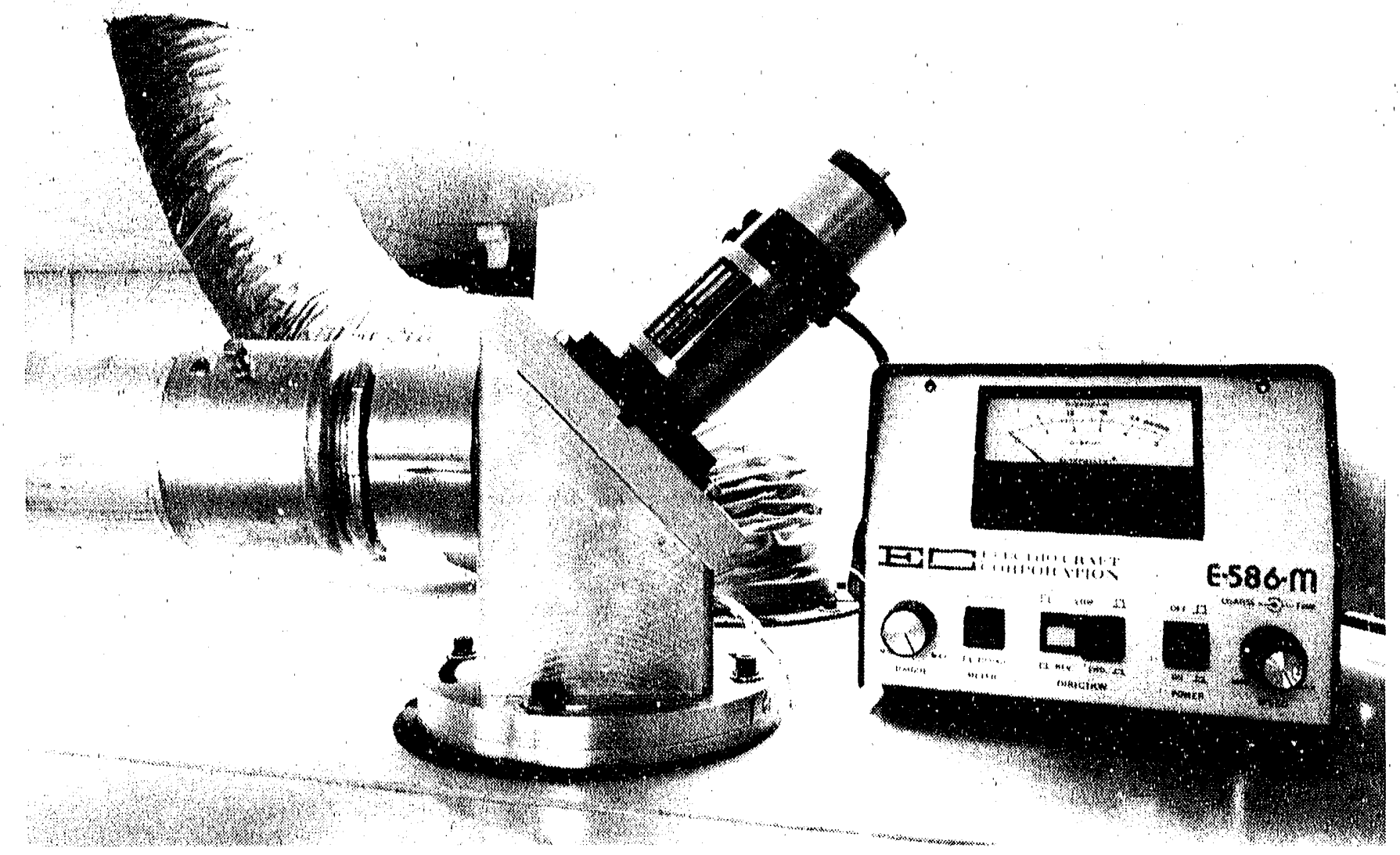

Figure 6. SNI, beam spinner installed on top of workstation

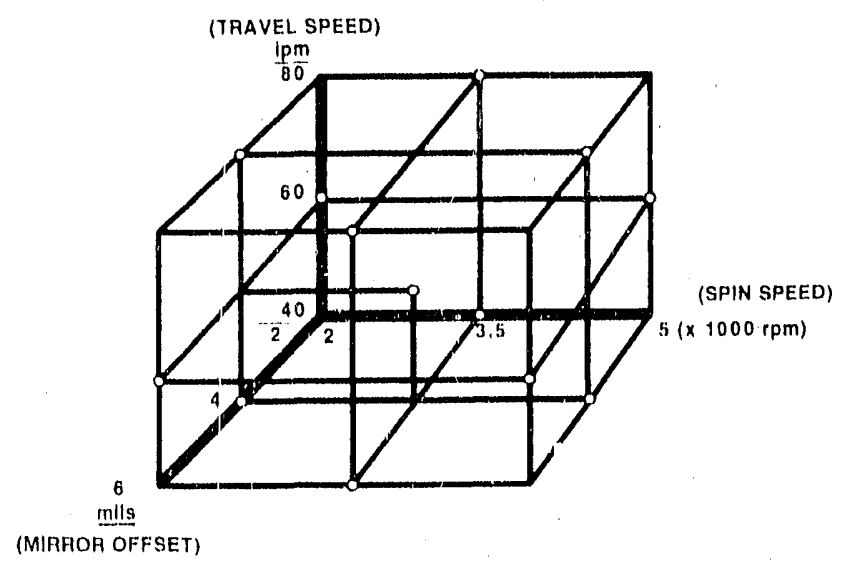

Figure 7. Schematic of fractional factorial design

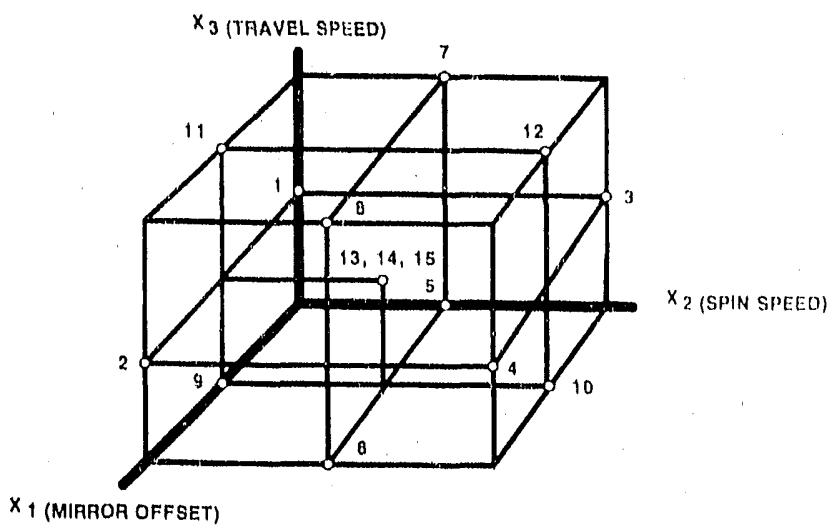

Figure 8. Schematic of fractional factorial design showing combinations of parameters 
We made bead-on-plate welds, sectioned the weld segments, measured the two response variables (depth of penetration and width of weld bead), and analyzed the data. Using a least-squares analysis technique, we arrived at predictor equations for the depth and the width. To entablish a level of confidence, I made multiple welds at zero spin speed and zero orfset at the three levels of welding speed, and multiple welds at the midpoint of the design (at 4-mil mirror offset, $3500 \mathrm{rpm}$ spin speed, and $60 \mathrm{ipm}$ welding travel speed).
T'he bead-on-plate welds were made on 0.056 in-thick milct-steel sheet using a Photon Sources $\mathrm{V} 120\left(\mathrm{CO}_{2}\right.$ laser operating at a constant continuous wave power of $805 \mathrm{~W}$ using argon lens gas, a 5-in. focal-length lens, and sharp surface forcus. A random sequence was used to make the welds in order to negate any time or sequence dependency. Four welds were made at each combination of parameters.

Figure 9' shows one of two workstations of the SNI, Albuquerque Photon Sources V1200 CO. laser. Figure 10 is a closeup view of the nozzle-workpiece. 'The workstation was used to make the coupons for this experiment.

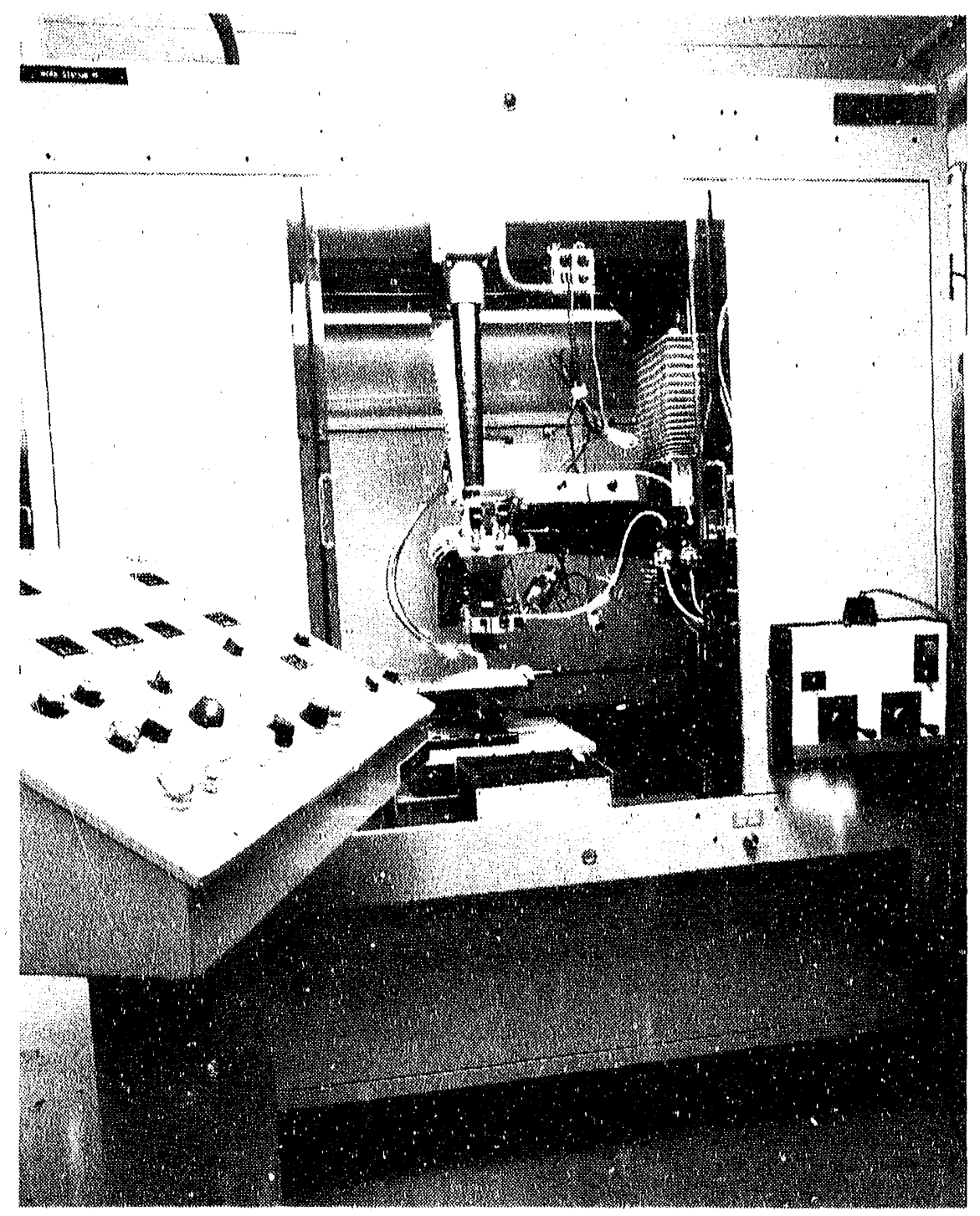

Figure 9. SNI, CO2, laser workstation 


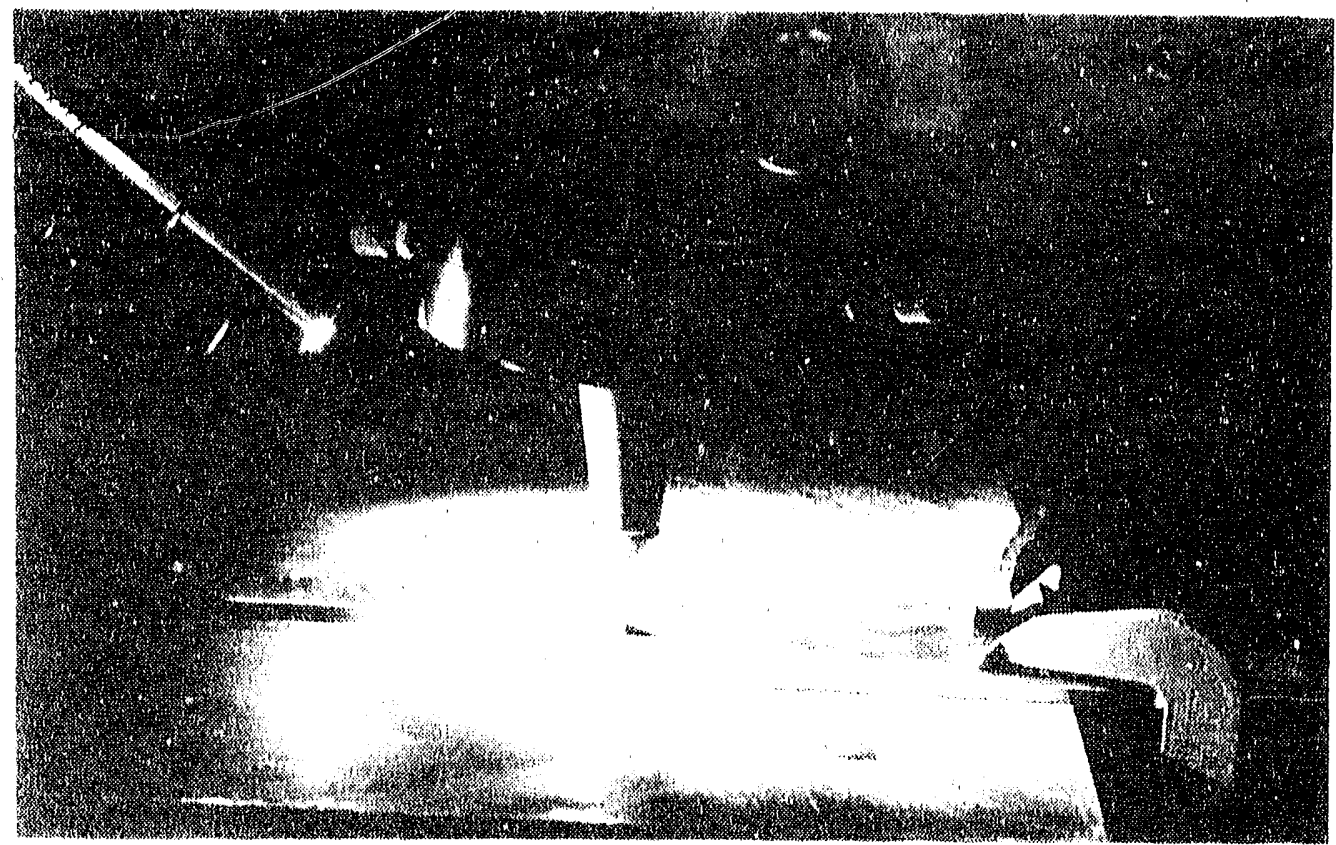

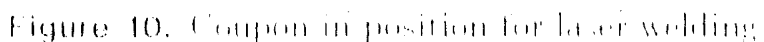

\section{Results}

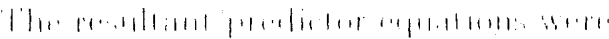

$11,111,11$

$$
\begin{aligned}
& \text { 1). 1\% } 111111,1 \\
& 1,1 \quad 111^{1} 131 \\
& 1111 \text { 111'1 1 } \\
& 1+1+1,11+1,121 \\
& \text {, llili 11, } \because, 1
\end{aligned}
$$

.1111

$|1,11| 1 \mid 1, \quad 11,1,11) \quad(1,101: 1, \because 1$

$$
\begin{aligned}
& 1,111^{1}, 4,1 \\
& 1,11,111^{4}, 1191
\end{aligned}
$$

$\because 1, \cdots$

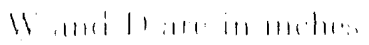

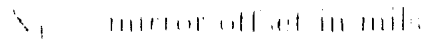

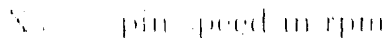

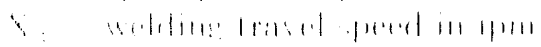

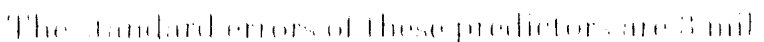

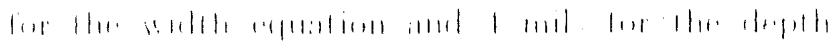

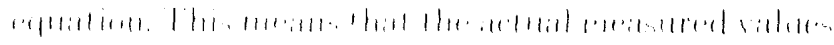

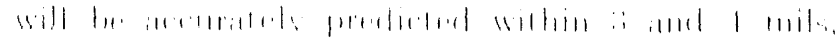

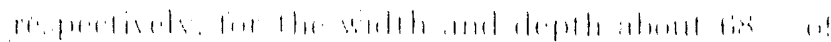
11111111.

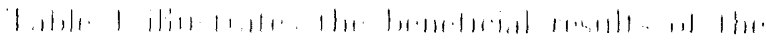

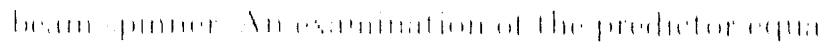

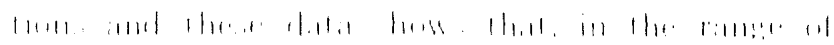

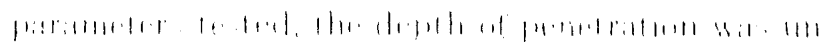

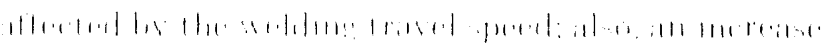

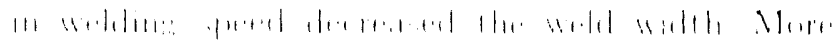

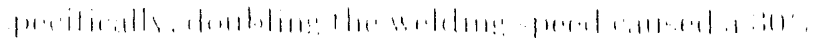

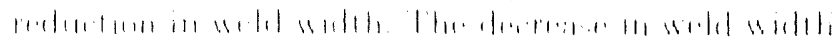

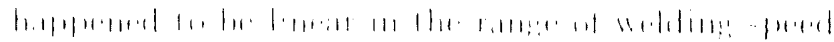
$|1| 1,,1 \mid$

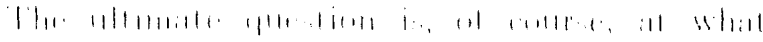

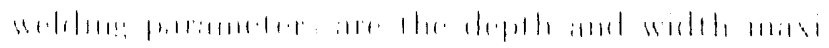

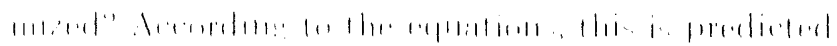

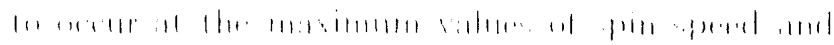

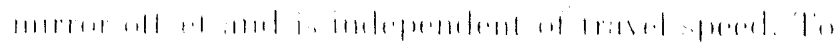

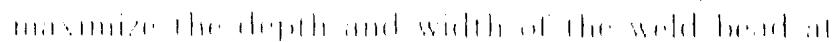

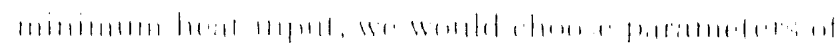

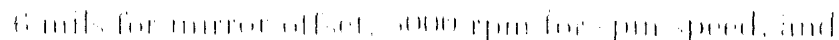

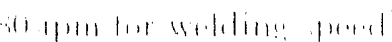




\section{Table 1. Results of Laser-Beam Spinning}

\begin{tabular}{cccccc} 
& $\begin{array}{c}\mathrm{X}_{1} \\
\text { Mirror Offset } \\
(\text { mils })\end{array}$ & $\begin{array}{c}\mathrm{X}_{2} \\
\text { Spin Speed } \\
(\mathrm{rpm})\end{array}$ & $\begin{array}{c}\mathrm{X}_{33} \\
\text { Welding Speed } \\
(\mathrm{ipm})\end{array}$ & $\begin{array}{c}\mathrm{D} \\
\text { Depth } \\
(\mathrm{in.})\end{array}$ & $\begin{array}{c}W \\
\text { Width } \\
\text { (in.) }\end{array}$ \\
\hline & 0 & 0 & 40 & 0.035 & 0.056 \\
& 0 & 0 & 60 & 0.035 & 0.048 \\
(Maximum) & 0 & 0 & 80 & 0.035 & 0.040 \\
(Midpoint) & 6 & 5000 & 80 & 0.035 & 0.200 \\
\hline
\end{tabular}

'Typical cross sections of welds are shown in Figure 11. 'These welds illustrate the increased width of the weld bead as the mirror off'set is increased. At the same time, tive depth of penetration does not change significantly.

Several coupons were fabricated to simulate the KCD production hardware. The rectangular insertin-socket coupons were fabricated with a 10-mil gap on two sides when the opposing sides are abutting (Figure 12), The parts were Nd-YAG laser spot- welded in that of fset position to simulate a "greatest gap" condition and were then $\mathrm{CO}_{2}$ laser-welded using the beam spinner and the parameters from the mid. point of the experimental plan matrix (4-mil mirror offset, $3500 \mathrm{rpm}$ spin speed, and $60 \mathrm{ipm}$ travel speed). The laser power was $805 \mathrm{~W}$.

A typical welded coupon is shown in Figure 13. The joint gap was closed without skips. Metallurgical examination showed the penetration to be 0.030 to $0.035 \mathrm{mil}$. 
(a)

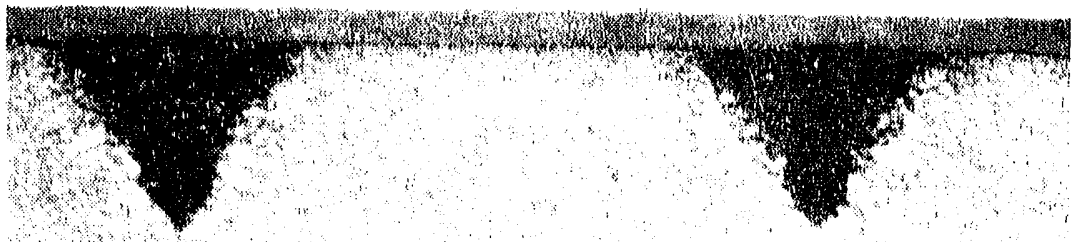

(b)
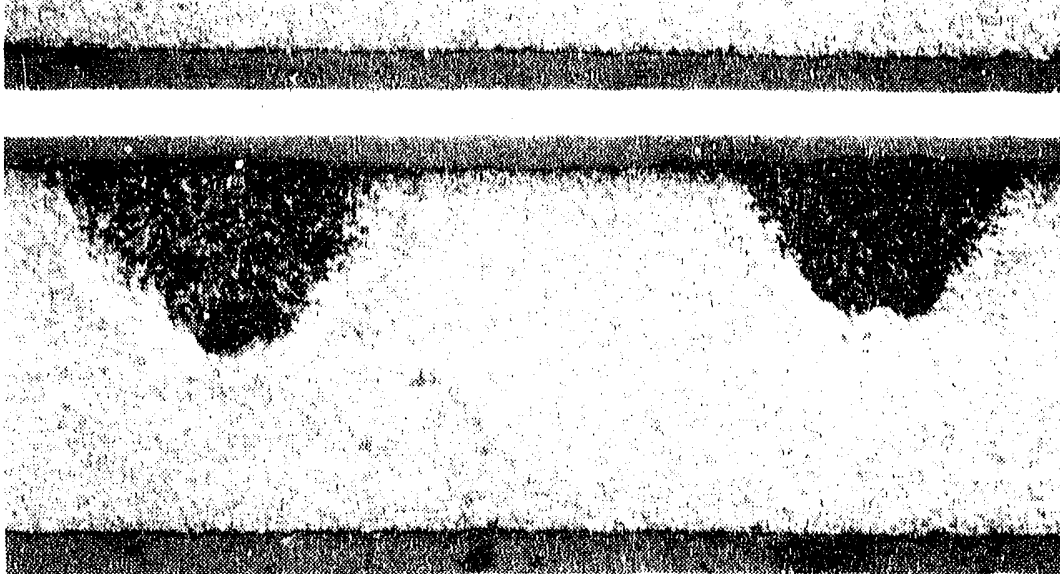

(c)
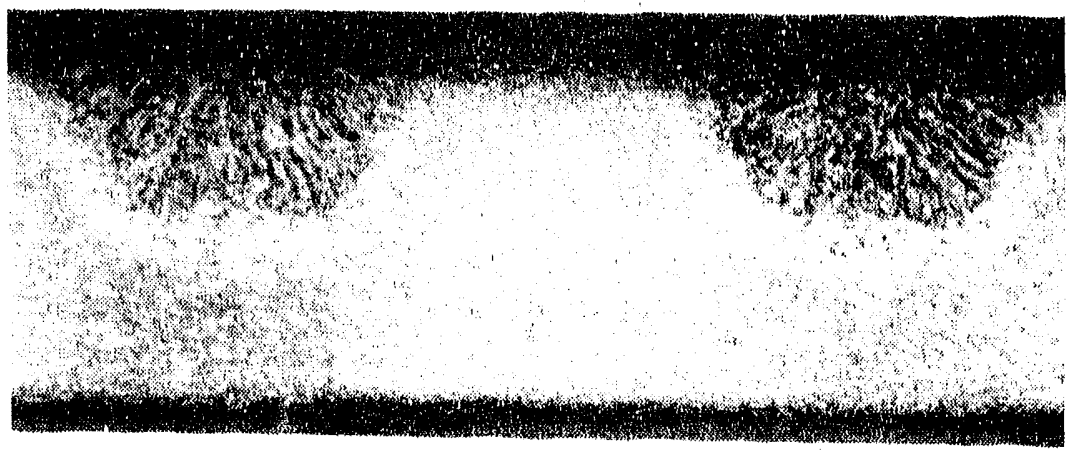

(d)

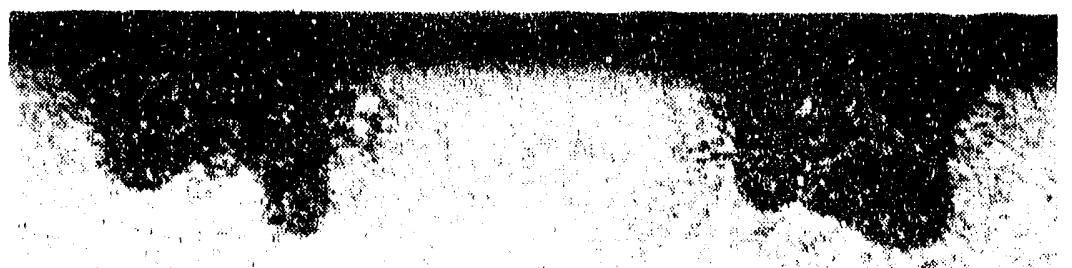

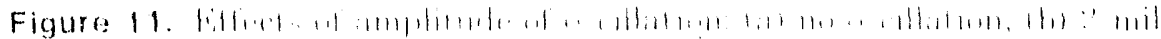

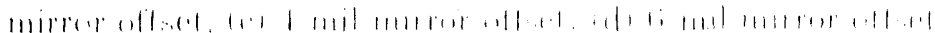




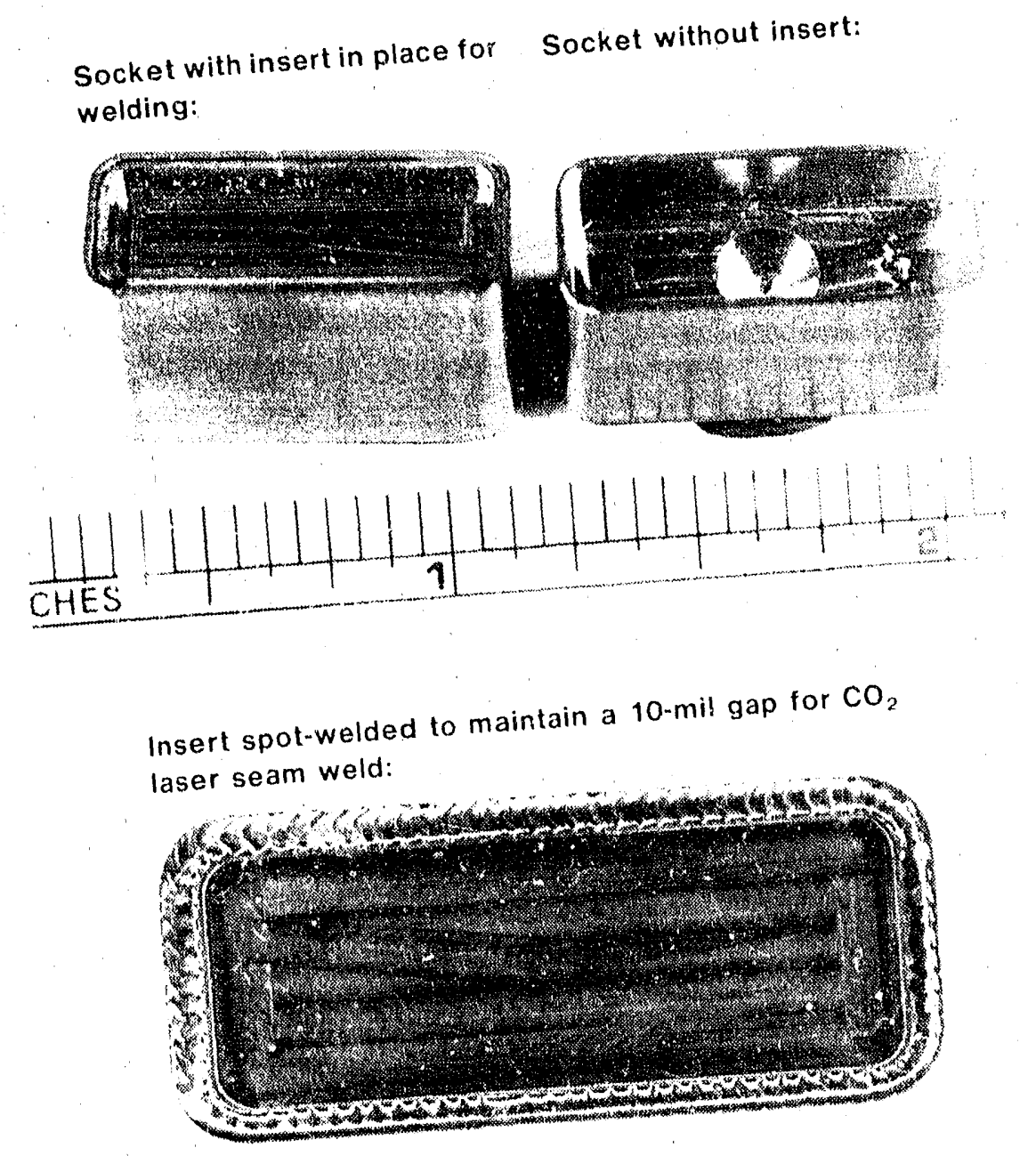

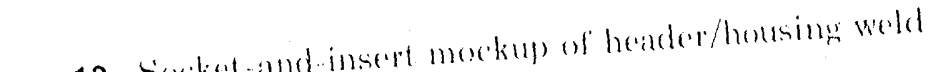

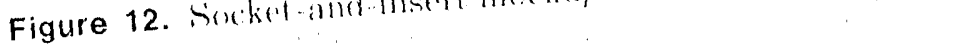




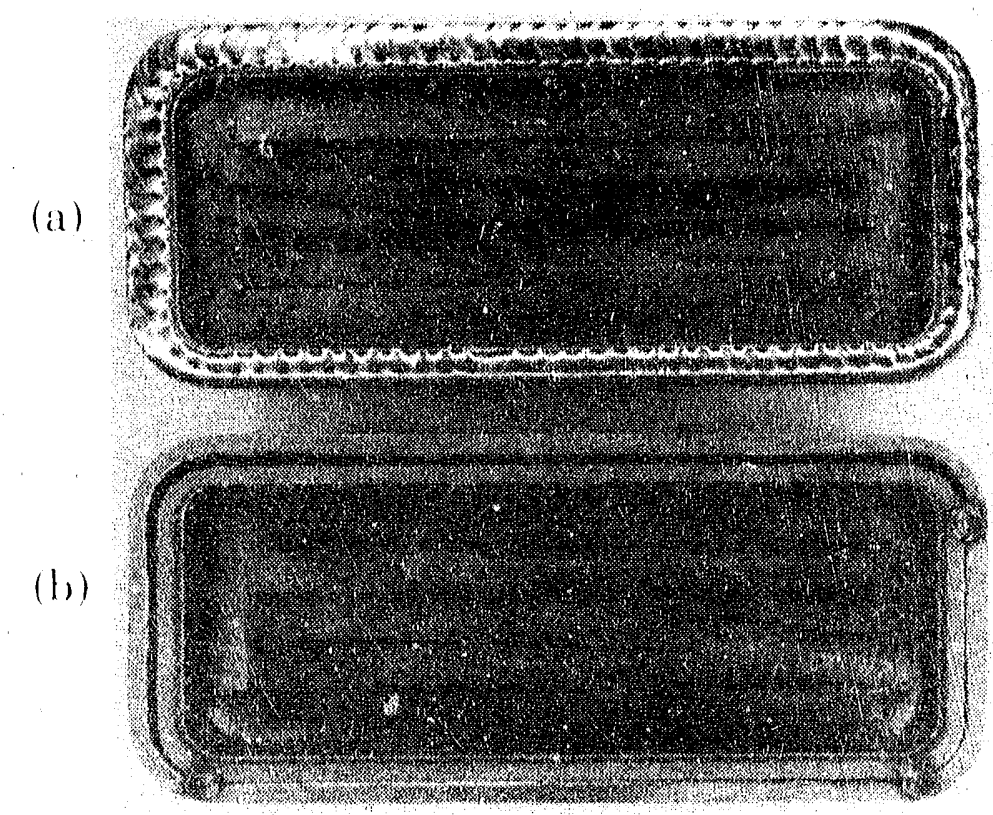

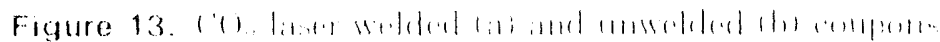

\section{Conclusions}

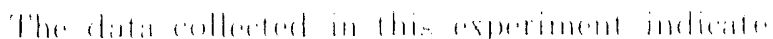

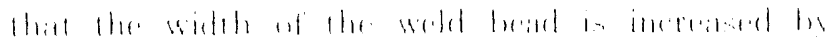

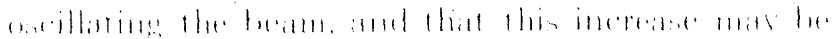

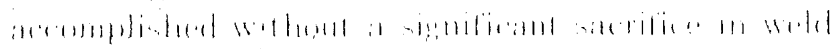

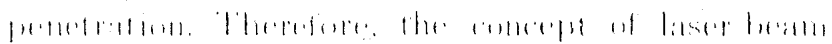

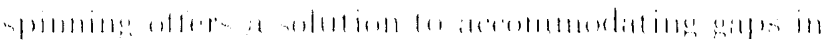

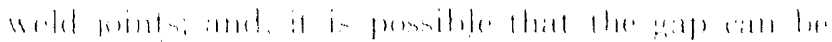

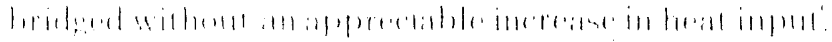



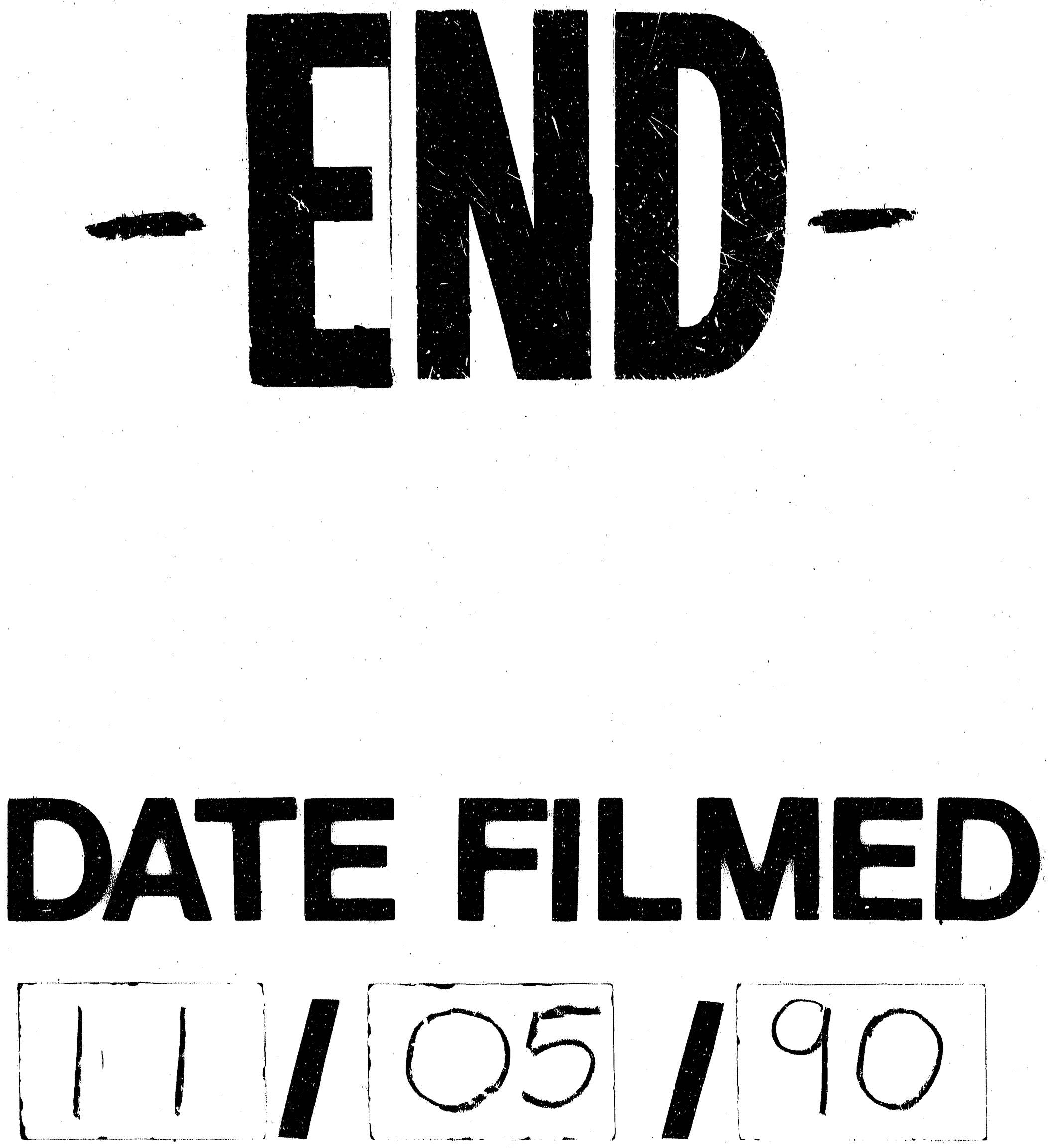
